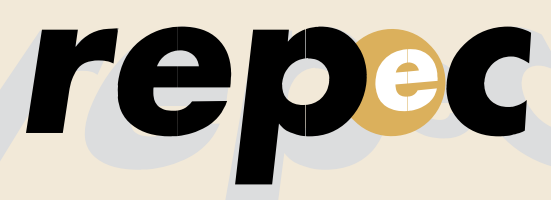

REPeC, Brasília, v. 11, n. 2, art. 5, p. 214-230, abr.jun. 2017 Disponivel online em www.repec.org.br DOl: http://dx.doi.org/10.17524/repec.v11i2.1531
Revista de Educação e Pesquisa em Contabilidade Journal of Education and Research in Accounting

Periódico Trimestral, digital e gratuito publicado pela Academia Brasileira de Ciências Contábeis

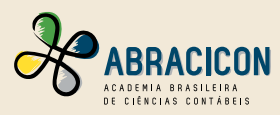

ISSN 1981-8610

\title{
O Que me Ensina a Ensinar? Um Estudo Sobre Fatores Explicativos das Práticas Pedagógicas no Ensino de Contabilidade
}

\begin{abstract}
Resumo
Este artigo identificou as práticas pedagógicas de 164 professores de Ciências Contábeis do Estado da Bahia, segregadas em ativas ou passivas, com maior ou menor participação discente, respectivamente. Aspectos como tipo de instituição de ensino, modalidade do ensino, experiência e capacitação pedagógica do docente, conteúdo programático, quantidade de alunos e avanço no curso foram posteriormente empregadas como possíveis variáveis explicativas das práticas. O diagnóstico construído com estatísticas descritivas e testes de Mann-Whitney revelou um ensino essencialmente passivo, com reduzida participação do discente. As variáveis independentes não foram capazes de explicar as práticas pedagógicas. Contradições foram encontradas no uso de práticas que caracterizam um ensino ativo como seminários, debates e discussão de casos por professores com marcantes características de ensino passivo, o que pode indicar um uso incompleto ou inadequado dessas práticas, que poderiam estar em uso de modo essencialmente passivo, comprometendo a eficácia da aprendizagem.
\end{abstract}

Palavras-chave: Práticas Pedagógicas. Ensino em Contabilidade. Ensino ativo.

\section{Uilcleides Braga da Silva}

Mestre em Contabilidade pela Universidade Federal da Bahia (UFBA) e Professora na Faculdade Maria Milza (FAMAN). Contato: Rodovia 101, Km 215, Governador Mangabeira/BA, CEP: 44.350-000. E-mail: uilcleidesbraga@yahoo.com.br

\section{Adriano Leal Bruni}

Doutor em Administração pela Universidade de São Paulo (USP) e Professor na Universidade Federal da Bahia (UFBA). Contato: Av. Reitor Miguel Calmon, s/n, Faculdade de Ciências Contábeis, Vale do Canela, Salvador/BA, CEP: 40.110-903.

E-mail: albruni@gmail.com 


\section{Introdução}

As mudanças normativas, tecnológicas, econômicas impactam diretamente as rotinas dos profissionais de contabilidade. A exigência do mercado por um profissional que, além de conhecimento técnico, seja capaz de julgar estrategicamente a maneira de avaliar e relatar as informações contábeis, de forma a dar o melhor suporte aos tomadores de decisões, são reflexos de tais mudanças, refletindo também na educação em Contabilidade. Critérios de mensuração como Valor Justo (fair value) ou contabilização de ativos intangíveis são exemplos de mudanças normativas ocorridas na Contabilidade e que trazem uma complexidade maior se comparadas a outros critérios de mensuração como custo histórico, por exemplo, exige do profissional habilidades critico-reflexivas (Magalhães, Santos \& Costa, 2010).

A discussão, então, está no processo de formação desses profissionais da Contabilidade. As Instituições de Ensino Superior (IES), em Contabilidade enfrentam um grande desafio de formar profissionais com as novas habilidades requeridas. A maneira tradicional, passiva e com menor envolvimento discente, pode não atender mais às necessidades e expectativas dos discentes, dos próprios docentes e às expectativas do mercado, visto que poderia não proporcionar uma ampla relação de interação e colaboração entre professor e aluno para o desenvolvimento da habilidade de reflexão crítica (Killian, Huber \& Brandon, 2012; Black, 2012; Coetzee \& Schmulian, 2012; Pereira, Niyama \& Freire, 2012). Faz-se necessário repensar sobre a forma de ensinar.

A melhor maneira de ensinar não é apresentada com clareza na literatura. Entretanto, existem diversas metodologias que podem aumentar o envolvimento do aluno no processo de ensino-aprendizagem. Na prática, julga-se existir um fraco alinhamento entre o que é discutido em sala ou a forma de condução dessa discussão e o que os alunos realmente utilizam ou fazem no cotidiano organizacional. Poderia ser uma falha no modo de ensinar que pode não contribuir de forma eficaz na formação do novo contador (Killian, Huber \& Brandon, 2012; Peleias, Patrucci, Garcia \& Silva, 2008). Conforme Silva, Bruni e Baqueiro (2013) - e Pereira, Niyama e Freire (2012), as práticas de um modelo tradicional, centralizado no professor, com simples transferência de informação e uma relação distante entre professor e aluno, persistem.

Caberia uma reflexão e investigação quanto à capacidade dos professores em contribuir para a formação do novo perfil de aluno, os atributos docentes e práticas mais adequadas para o desenvolvimento de habilidades necessárias para atuação contábil, ou as qualificações que se fazem necessárias para a docência. Essa discussão torna-se relevante no sentido de que a formação de profissionais da Contabilidade influencia diretamente o universo empresarial, uma vez que esse tipo de profissional cumpre o papel importante de fornecer informações aos tomadores de decisões de empresas e, consequentemente, no equilíbrio econômico-social em que as empresas estão inseridas, bem como são impactados pelas exigências mercadológicas que exigem profissionais com habilidades de julgamento e reflexão de forma crítica, de comunicação e organização da informação, e não somente conhecimentos específicos de técnicas de mensuração, avaliação e apresentação de relatórios contábeis. E o corpo docente das instituições de ensino tem ligação direta com a formação deste novo perfil de contadores.

O presente artigo inicia um conjunto de atividades de pesquisa com o propósito de entender e, a partir dessa compreensão, propor, em pesquisas futuras, melhorias para o ensino de Contabilidade no Estado da Bahia; objetiva construir um diagnóstico das práticas pedagógicas empregadas, analisando condicionantes para uma prática mais ativa ou mais passiva. O problema de pesquisa consistiu em: como as práticas pedagógicas adotadas no ensino de Contabilidade no Estado da Bahia podem ser explicadas a partir das variáveis capacitação e experiência pedagógica do docente, tipo de IES, modalidade de ensino, conteúdo, quantidade de alunos na turma e grau de avanço no curso? 


\section{Práticas Pedagógicas no Ensino em Contabilidade}

A escolha adequada da prática pedagógica pode ser um diferencial na formação de uma profissional, a depender de como é desenvolvido o processo de aprendizagem, foco das estratégias adotadas para desenvolver as habilidades de julgamento e tomada de decisão (Martins, Vasconcelos \& Monte, 2009). O ensino de Contabilidade pode ser tratado sob duas abordagens: abordagem passiva ou tradicional, centralizada no professor como sujeito ativo no processo de aprendizagem e a abordagem ativa ou não tradicional, centrado no aluno.

O ensino na perspectiva tradicional considera o professor como sujeito principal no processo de aprendizagem, ser conhecedor de todo o conhecimento. Esse modelo tradicional, conforme Coetzee e Schmulian (2012, p. 87), "é caracterizado pelo professor dominar a sala de aula, dando resmas de conhecimento para os alunos, de quem pouco se espera além de passivamente absorver o conhecimento". Consiste em um meio de transferência de conhecimento, em que o aluno tem a função de memorizar os conetudos apresentados pelo professor. Fazem parte das práticas pedagógicas sobre uma concepção tradicional do ensino: aulas expositivas fundamentadas em livros textos, didáticos, memorização de conteúdos sintetizados; a utilização de critérios objetivos de avaliação como prova escrita com respostas fechadas, ou, até mesmo, questões discursivas que levem o aluno a regurgitar uma série de informações transmitidas pelo professor durante as aulas (Pereira, Niyama \& Freire, 2012, Black, 2012). A concepção bancária de Freire (1987) corrobora o modelo tradicional de ensino, em que o conteúdo contido em livros didáticos recebe demasiada atenção, e os alunos são peças sem ação no processo de ensino.

$\mathrm{O}$ ensino, uma perspectiva ativista, fundamenta-se nas ideias e teorias construtivistas de Piaget e seus seguidores. Corresponderia a "uma série de teorias que remetem ao estudo do desenvolvimento cognitivo e o desenvolvimento interacionista do ser humano, também conhecido pelo nome de construtivismo" (Oliveira, 2009, p.27). O conhecimento se constrói a partir de uma série de atividades, sejam elas relacionadas a atividades mentais, cognitivas ou mesmo relacionadas a aspectos culturais e sociais para o desenvolvimento de estruturas organizadas de informações e construção do saber.

O ensino, nesse aspecto, segundo Oliveira (2009, p. 27), "deve visar ao desenvolvimento da inteligência por meio do construtivismo interacionista, que, em essência, parte do princípio de que o que é assimilado é agregado a uma estrutura mental anterior, criando-se uma nova estrutura em seguida”. Na visão construtivista, o conhecimento não é considerado algo estático, pronto e acabado. Caracteriza-se algo mais particular, exclusivo de cada aluno, visto que o conhecimento não seria transferido e, sim, construído. Sobre esse fundamento, ensinar não pode resumir-se a uma simples transferência de conteúdos disciplinares sem ao menos considerar o "receptor", no caso, o aluno, sem interação com o meio onde está inserido, os conhecimentos adquiridos por ele ao longo dos anos, como uma peça solta e sem participação. De acordo com Oliveira (2009, p. 27), "por uma concepção construtivista de ensino, a função educacional consiste em criar, construir, vivenciar realidades com uma interação entre os indivíduos”.

Conforme Veiga (2008), prática pedagógica pode ser definida como prática social orientada por objetivos, finalidades e conhecimentos de caráter social, abrangendo diferentes aspectos em relação à escola e o contexto em que está inserida. Ainda, conforme Veiga (2008, p. 16), é entendida como "uma dimensão da prática social que pressupõe a relação teoria-prática, e é essencialmente nosso dever como educadores, a busca de condições necessárias à sua realização". As práticas pedagógicas adotadas variam entre práticas mais passivas ou mais ativas. Para Tozetto e Gomes $(2009,190)$, a "prática pedagógica é a ação de professores para um ensino e dependendo da prática o ensino pode melhorar ou também piorar". Para Slomski e Martins (2008, p. 9), "a prática pedagógica é entendida como um espaço de construção dos saberes profissionais".

As práticas pedagógicas poderiam ser apresentadas como ativas ou passivas. Sua caracterização pode ser vista no Quadro 1. 
Quadro 1

Práticas pedagógicas ativas e passivas

\begin{tabular}{|c|c|}
\hline Ensino passivo & Ensino ativo \\
\hline \multicolumn{2}{|c|}{ Caracterização } \\
\hline $\begin{array}{l}\text { Assume o professor como centro das atenções, } \\
\text { o "conhecedor de todo o saber". Existe uma } \\
\text { reduzida participação do discente no processo } \\
\text { de ensino que, passivamente, deveriam absorver } \\
\text { ou memorizar o conhecimento transmitido pelo } \\
\text { professor. }\end{array}$ & $\begin{array}{l}\text { Assume que o conhecimento se constrói a partir de uma } \\
\text { série de atividades para o desenvolvimento de estruturas } \\
\text { organizadas de informações e construção do saber. O } \\
\text { aprendizado acontece a partir de organização esquemas } \\
\text { de ações estruturadas em função das experiências vividas } \\
\text { e do meio onde o aluno vive. }\end{array}$ \\
\hline \multicolumn{2}{|c|}{ Práticas pedagógicas usuais } \\
\hline $\begin{array}{l}\text { Envolvem ações que levem os alunos a } \\
\text { memorização de conteúdos. Exemplos: aulas } \\
\text { puramente expositivas, sem participação do } \\
\text { aluno, apostilas com conteúdo sintetizado, } \\
\text { listas de exercícios, livro texto, sem espaço para } \\
\text { discussão, com critérios objetivos de avaliação } \\
\text { de desempenho do aluno, como prova escrita, } \\
\text { com questões de múltipla escolha, que remeta o } \\
\text { aluno a práticas de memorização e reprodução de } \\
\text { conteúdos sintetizados pelo professor. }\end{array}$ & $\begin{array}{l}\text { Envolvem ações que levem os alunos a uma participação } \\
\text { mais intensa no processo de aprendizagem. Exemplos: } \\
\text { aulas expositivas dialogadas; estudos dirigidos; } \\
\text { aprendizagens experienciais a partir de entrevistas com } \\
\text { profissionais no mercado, seminários com toda a classe, } \\
\text { mesa redonda, debates, com a participação de todos } \\
\text { os alunos, aprendizagem baseada em problemas (PBL); } \\
\text { ensino em pequenos grupos, ensino com pesquisa; ensino } \\
\text { à distância (como grupos de discussão online); estudo } \\
\text { de casos; ensino com pesquisa; oficinas (laboratórios ou } \\
\text { workshops); escritórios, laboratórios ou empresas modelo; } \\
\text { simulações e jogos. }\end{array}$ \\
\hline
\end{tabular}

Fonte: adaptado de Silva (2014).

Práticas pedagógicas passivas estariam associadas a um modelo tradicional de ensino, com enfoque enciclopédico, em que o docente opera como transmissor do conhecimento. Práticas tradicionais envolveriam aulas expositivas, com a apresentação de conteúdos sintetizados de acordo com o ponto de vista do professor, sem muita reflexão e interação entre professor e aluno (Zanon \& Althaus, 2010). Quanto ao critério de avaliação do desempenho do aluno, o mais utilizado é prova escrita com questões objetivas e discursivas, levando o aluno a uma memorização de conteúdos apresentados pelos professores (Pereira, Niyama \& Freire, 2012).

No contexto das práticas ativas, variadas opções permitiram inserir o aluno como sujeito ativo no processo de construção do conhecimento. Muito tem sido discutido sobre a necessidade de abordar as práticas pedagógicas, com ações voltadas para o aluno, até mesmo em disciplinas introdutórias de Contabilidade e Finanças, conforme Killian, Huber e Brandon (2012); Cunninghan (2011); Premuroso, Tong e Beed (2011). Como bem retratam Killian, Huber e Brandon (2012), quando mencionam a "aprendizagem intencional", em que deve ser despertado no aluno a habilidade de aprender intencionalmente e se tornar aprendiz durante o longo da vida, acreditam no uso de entrevistas com profissionais experientes no assunto a ser estudado, Cunninghan (2011) aborda o uso de palestras e peças teatrais como estratégias pedagógicas, enquanto Premuroso, Tong e Beed (2011) argumentam sobre o uso de tutoriais para promover uma interação pedagógica e melhoria no processo de ensino-aprendizagem. Ainda existe uma lacuna entre as práticas pedagógicas ideais sugeridas na literatura e a forma como se dá o ensino em Contabilidade no Brasil (Pereira, Niyama \& Freire, 2012). 


\section{Procedimentos Metodológicos}

O objetivo de diagnosticar o ensino de Contabilidade na Bahia levou à realização de pesquisa quantitativa. O procedimento de coleta de dados evolveu o uso de questionários, coletados com o auxílio da ferramenta SurveyMonkey. Foi feito um levantamento das instituições cadastrada no sistema E-MEC que oferecem o curso de Contabilidade e consultados os websites institucionais para levantar os emails dos coordenadores. Posteriormente, mensagem eletrônica foi enviada para cada um dos coordenadores com a solicitação da lista dos e-mails dos docentes. Em seguida, foram enviados 1.213 e-mails com o convite para o preenchimento do questionário; destes, 164 colaboraram com a pesquisa.

Os diagnósticos das práticas pedagógicas adotadas e atuação docente do respondente foram realizados a partir de afirmações contidas nos Blocos de I a V da segunda seção do instrumento de coleta de dados. O instrumento de coleta de dados foi elaborado e estruturado em blocos para melhor organização e alcance dos objetivos propostos. Os Blocos I a IV foram adaptados do instrumento utilizado por Silva et al. (2013).

As afirmações dos Blocos I ao Bloco IV buscaram diagnosticar as práticas pedagógicas das instituições de ensino. $\mathrm{O}$ Bloco $\mathrm{V}$ refere-se à qualificação e atuação profissional e docente do respondente. $\mathrm{O}$ Bloco I contém perguntas sobre o planejamento e condução das aulas, afirmações identificadas de $\mathrm{C} 1$ a C8. O Bloco II, formado pelas afirmações de $\mathrm{C} 9$ a C15, refere-se às práticas pedagógicas mais utilizadas pelos professores, buscando identificar a partir de uma escala do tipo de Likert, com dois extremos de intensidade, em que 1 representa uma discordância total da afirmação apresentada e 7 total concordância. O Bloco III, formado pelas afirmações de C16 a C19, buscou identificar os recursos utilizados pelos professores para ministrar suas aulas; objetivou identificar a intensidade na utilização de recursos como retroprojetor, quadro, data show, filmes ou recursos de áudio. O Bloco IV buscou identificar os critérios adotados pelos professores para avaliar o desempenho do aluno; foi formado por sete afirmações para que os respondentes pudessem se manifestar em uma escala de intensidade, do tipo Likert com sete pontos, com dois extremos de intensidade, que varia de 1 a 7, onde 1 representa uma discordância total da afirmação apresentada e 7 total concordância.

O Bloco V foi formado pelas perguntas identificadas de D1 a D13; buscou-se coletar informações sobre a capacitação pedagógica do docente, tipo de instituição, experiência, característica da disciplina, quantidade média de alunos em sala, bem como outras informações como gênero, idade, formação profissional dos respondentes.

O objetivo da constatação das práticas pedagógicas adotadas e a atuação docente coletados com as perguntas deste bloco envolve uma posterior análise de associação de cada variável com uso de práticas ativas ou passivas. Os dados levantados servem para testar as hipóteses apresentadas a seguir.

Ha: Maior capacitação pedagógica dos docentes está associada à escolha de práticas pedagógicas ativas.

No que se refere à formação para o exercício da docência, Miranda, Casa Nova e Cornacchione Junior (2012) apresentam a formação profissional e a capacitação pedagógica como fatores importantes para o exercício da profissão. Contudo, a literatura não faz menção de forma clara que capacitação pedagógica está associada à utilização de práticas pedagógicas ativas.

Hb: Docentes de instituições públicas estão mais propensos a utilizarem com maior intensidade práticas pedagógicas ativas. 
As instituições de ensino são categorizadas em dois grandes grupos: instituições públicas e privadas. Cabe ressaltar alguns aspectos que diferenciam os dois tipos de instituições: (a) forma de financiamento - as instituições públicas são financiadas pelo Poder Público a partir de repasse de verbas públicas; já as instituições particulares são financiadas com os recursos arrecadados com cobrança de valores desembolsados pelos alunos, como ratifica Silva (2001, p.296) de que a "dependência da clientela para a sobrevivência econômica da empresa gerava naturalmente um nivelamento por baixo das exigências didáticas"; (b) questões salariais dos docentes; (c) o envolvimento das instituições públicas com a pesquisa científica diferentemente das instituições particulares que focam na formação técnica (Silva, 2001); (d) a titulação do corpo docente, existe uma concentração maior de mestres e doutores nas instituições públicas do que nas instituições privadas (Martins, Vasconcelos \& Monte, 2009); e outros aspectos com infraestrutura da instituição, políticas administrativas. Presume-se que, pelos aspectos apresentados anteriormente, em instituições públicas, o uso de práticas pedagógicas ativas é mais comum devido ao envolvimento dos professores e alunos com vivência como pesquisadores e pela dedicação exclusiva a docência do que em instituições privadas, em que comumente os professores de instituições particulares aparecem próximos ao horário de irem para as salas de aula e não exercem grandes atividades de pesquisa com os alunos devido ao regime de trabalho e remuneração recebida como contrapartida.

Hc: Professores com maior atuação no ensino presencial estão mais associados ao uso de práticas pedagógicas ativas.

A modalidade de ensino pode explicar, em parte, o uso das práticas pedagógicas mais ou menos ativas. Um curso presencial pode requerer de um professor maior interação com os alunos, visto que estes são figuras presentes exigindo maior diálogo, o que pode facilitar a utilização de metodologias ativas, como dinâmicas de grupos, seminários. Na literatura não foram encontrados trabalhos capazes de fundamentar tal julgamento de forma explícita.

Hd: Professores com maior experiência acumulada estão associados à escolha das práticas pedagógicas ativas.

Refere-se como experiência nesta pesquisa a experiência profissional e experiência em docência. A experiência profissional pode influenciar a utilização de práticas ativas de ensino mais adequadas às necessidades trazidas pelo contexto atual de Contabilidade, visto que um profissional experiente já deve ter sentido as dificuldades de enfrentar obstáculos reais no desempenho da profissão. Assim também, a experiência em docência pode influenciar positivamente a adoção de práticas pedagógicas ativas, uma vez que o professor aprende atuando em sala; as práticas pedagógicas que melhor adéquam às características da disciplina, da turma e assim, por meio da observação de sucesso ou fracasso na escolha de uma ou de outra metodologia para ensinar. Na concepção de Miranda, Casa Nova e Cornacchione Junior (2012); Killian, Huber e Brandon (2012); Black (2012); Nóvoa (2009); Maseto (2009); e Slomski (2007), o saber fazer é adquirido a partir de uma série de vivências práticas, ou seja, a partir do acumulo de experiências acontece a melhoria na qualidade da atividade desempenhada.

He: Professores que lecionam disciplinas mais práticas ou aplicadas estariam associados com maior intensidade ao uso de práticas pedagógicas ativas. 
Outro ponto que pode estar associado à escolha de práticas pedagógicas é a característica do conteúdo programático da disciplina. Pesquisadores como Black (2012), Pereira, Niyama e Freire (2012) consideram o conteúdo disciplinar como uma variável direcionadora na forma de ensinar, ou seja, as práticas pedagógicas adotadas pelos docentes podem alterar conforme essa variável. Como argumento para esta hipótese, o conteúdo programático é segregado, para este trabalho, em dois grupos: conteúdos de teóricos, conceituais ou normativos (caso da disciplina Teoria da Contabilidade) e conteúdos práticos ou aplicados (como é o caso das disciplinas Contabilidade de Gerencial, Análise de Custos), que podem direcionar o professor à escolha de práticas mais ativas em disciplinas conteúdos práticos ou aplicados enquanto em disciplinas com conteúdos mais teóricos e conceituais podem adotar práticas pedagógicas passivas. Por exemplo, a utilização de laboratórios para algumas disciplinas mais práticas, ou até trabalhos teórico-científicos em disciplinas mais teóricas (Kosová, 2014).

Hf: Os professores que lecionam em turmas com menor quantidade de alunos estão associados ao uso mais intenso de práticas pedagógicas ativas.

O número de alunos matriculados em cursos superiores vem aumentando, juntamente com a pressão sobre as instituições de ensino por profissionais qualificados, a escassez de recursos financeiros aplicados no setor, e ainda a falta de profissionais capacitados (Miranda, Casa Nova \& Cornachione Jr., 2012). Esse aumento de alunos e a exigência do mercado por profissionais reflexivos podem interferir diretamente na maneira de lecionar. Como argumentam Maringe e Sing (2014, p.4), a grande quantidade de alunos em sala de aula "não é, portanto, apenas uma questão de números, mas é uma questão das complexidades e desafios associados com a entrega de ambos igualdade e qualidade oportunidades para todos os alunos a aprender". Considerando as características das metodologias ativas, caracterizada pela inclusão do aluno como sujeito ativo no processo de aprendizagem e sua interação, considera-se que a existência de turmas muito cheias pode interferir na discussão e interação do aluno com o professor e demais colegas, favorecendo o uso de metodologias passivas como aulas expositivas.

Hg: Professores que lecionam em turmas com grau de mais elevado de avanço no curso estão associados ao uso com maior intensidade de práticas pedagógicas ativas.

Acredita-se que o professor que leciona em turmas iniciantes tende a adotar mais práticas pedagógicas passivas do que em turmas mais avançadas no curso. Os alunos recém-chegados possuem um nível menor de entrosamento, o que talvez dificultasse o emprego de metodologias ativas. Adicionalmente, o conhecimento reduzido sobre temas de Contabilidade poderia elevar o desafio associado à utilização de práticas pedagógicas ativas como utilização de estudos de casos ou jogos com simulações.

Para a análise da constatação e atuação dos docentes, o teste não paramétrico de Mann-Whitney foi utilizado para a tentativa de verificar a média das respostas para práticas pedagógicas mais passivas difere da média de respostas para práticas mais ativas em relação ao estado de conclusão de curso, tipo de instituição de ensino, modalidade de ensino, conteúdo programático, experiência profissional e docente e capacitação pedagógica, assumindo a variável dependente (prática pedagógica) como dummy (0 - docentes com maior uso de práticas passivas e 1 - docentes com maior uso de práticas ativas).

\section{Análise das Constatações}

A amostra final foi composta por 164 respondentes, sendo que nem todos preencheram completamente o questionário. Os totais de respondentes apresentados nas tabelas e análises variam para cada tipo de pergunta, pois não foram respondidas todas as perguntas pelos respondentes. 
Das 109 respostas obtidas sobre gênero, 72 (66\%) revelaram ser do gênero masculino e 37 (34\%) do feminino; 63 respondentes possuíam idade acima de 40 anos; a escolaridade foi manifestada por 97 respondentes, sendo que 50 possuíam graduação em Contabilidade, 19 em Administração e 28 em outras áreas como Direito, Sistema de Informação, Engenharia Civil, Estatística, Matemática e Economia. Adicionalmente, 38 respondentes possuíam especialização em Contabilidade e Auditoria, 17 em Administração, 10 em Ensino e 18 em outras áreas (como Direito, Sistema de Informação, Políticas Públicas e Desenvolvimento Regional, Marketing).

Dos respondentes que revelaram possuir mestrado, 21 revelaram ter em Contabilidade, dez em Administração e 30 em outras áreas de conhecimento como Direito, Economia, Desenvolvimento Humano, Desenvolvimento Regional e Meio Ambiente, Computação e Antropologia Social; 4 respondentes revelaram possuir doutorado em Contabilidade, três em Administração, três em Educação e 5 em outras áreas (Desenvolvimento Regional, Computação e Economia).

Um bloco específico do instrumento coletou as práticas pedagógicas mais adotadas pelos respondentes, como planejamento e condução das aulas, a forma e os recursos utilizados para ministrar as aulas. No que diz respeito ao planejamento das disciplinas, foram constatadas as práticas dos docentes por meio de uma sequência de afirmações sobre a intensidade de participação dos alunos no planejamento das disciplinas conforme Tabela 1.

Tabela 1

Forma de planejar as aulas

\begin{tabular}{|c|c|c|c|c|c|c|c|c|c|c|}
\hline & & $\begin{array}{c}\text { Discordo } \\
1\end{array}$ & 2 & 3 & 4 & 5 & 6 & $\begin{array}{c}\text { Concordo } \\
7\end{array}$ & Média & Total \\
\hline \multirow{2}{*}{$\begin{array}{l}\text { C1. Os alunos participam muito } \\
\text { do planejamento das minhas } \\
\text { disciplinas. }\end{array}$} & $\mathrm{Fi}$ & 14 & 21 & 25 & 24 & 16 & 7 & 5 & 3,4 & 112 \\
\hline & $\%$ & 13 & 19 & 22 & 21 & 14 & 6 & 4 & & 100 \\
\hline \multirow{2}{*}{$\begin{array}{l}\text { C2. Os objetivos das minhas } \\
\text { disciplinas são sempre apresentados } \\
\text { aos alunos. }\end{array}$} & $\mathrm{Fi}$ & 1 & 1 & 1 & 4 & 3 & 14 & 88 & 6,6 & 112 \\
\hline & $\%$ & 1 & 1 & 1 & 4 & 3 & 13 & 79 & & 100 \\
\hline \multirow{2}{*}{$\begin{array}{l}\text { C3. Os conteúdos a serem } \\
\text { trabalhados nas minhas disciplinas } \\
\text { são sempre apresentados aos } \\
\text { alunos. }\end{array}$} & $\mathrm{Fi}$ & - & - & 2 & 2 & 6 & 10 & 90 & 6,7 & 110 \\
\hline & $\%$ & - & - & 2 & 2 & 5 & 9 & 82 & & 100 \\
\hline \multirow{2}{*}{$\begin{array}{l}\text { C4. Eu sempre apresento para os } \\
\text { alunos a metodologia que será } \\
\text { desenvolvida ao longo das minhas } \\
\text { aulas. }\end{array}$} & $\mathrm{Fi}$ & - & - & 2 & 6 & 11 & 21 & 72 & 6,4 & 112 \\
\hline & $\%$ & - & - & 2 & 5 & 10 & 19 & 64 & & 100 \\
\hline \multirow{2}{*}{$\begin{array}{l}\text { C5. Eu sempre apresento para os } \\
\text { alunos os critérios de avaliação nas } \\
\text { minhas disciplinas. }\end{array}$} & $\mathrm{Fi}$ & - & 1 & 2 & 4 & 5 & 16 & 83 & 6,5 & 111 \\
\hline & $\%$ & - & 1 & 2 & 4 & 5 & 14 & 75 & & 100 \\
\hline \multirow{2}{*}{$\begin{array}{l}\text { C6. Eu sempre apresento aos } \\
\text { alunos os recursos de apoio (textos, } \\
\text { equipamentos e outros) que } \\
\text { utilizarei nas minhas disciplinas. }\end{array}$} & $\mathrm{Fi}$ & - & 2 & 3 & 7 & 10 & 30 & 59 & 6,2 & 111 \\
\hline & $\%$ & - & 2 & 3 & 6 & 9 & 27 & 53 & & 100 \\
\hline \multirow{2}{*}{$\begin{array}{l}\text { C7. Eu sempre discuto o conteúdo } \\
\text { programático das minhas disciplinas } \\
\text { com os meus alunos. }\end{array}$} & $\mathrm{Fi}$ & 5 & 7 & 8 & 10 & 18 & 20 & 44 & 5,4 & 112 \\
\hline & $\%$ & 4 & 6 & 7 & 9 & 16 & 18 & 39 & & 100 \\
\hline \multirow{2}{*}{$\begin{array}{l}\text { C8. Eu sempre considero as } \\
\text { eventuais contribuições dos meus } \\
\text { alunos em relação às minhas } \\
\text { disciplinas. }\end{array}$} & $\mathrm{Fi}$ & - & 2 & 5 & 7 & 13 & 31 & 53 & 6,0 & 111 \\
\hline & $\%$ & - & 2 & 5 & 6 & 12 & 28 & 48 & & 100 \\
\hline
\end{tabular}

Fonte: dados da pesquisa (2014). 
Os números da Tabela 1 ressaltam a declaração de intensa participação intensa do professor no planejamento das disciplinas, com a apresentação de objetivos, conteúdos a serem trabalhados, metodologia, critérios de avaliação, recursos de apoio (textos, equipamentos e outros) para os alunos. A participação dos alunos no planejamento das disciplinas não acontece ou acontece de forma pequena. O planejamento da disciplina seria quase que unilateral, com o professor direcionando e apresentando as regras sem muita participação ou discussão com os alunos, que caracterizaria o ensino em uma perspectiva passiva, conforme Coetzee e Schmulian (2012), Pereira, Niyama e Freire (2012). Na fase de planejamento é que o professor elabora suas estratégias para trabalhar o conteúdo programático com os alunos, como devem ser trabalhados, com ou sem a participação dos alunos.

Tabela 2

Atividades empregadas em sala de aula

\begin{tabular}{|c|c|c|c|c|c|c|c|c|c|c|}
\hline & & $\begin{array}{c}\text { Discordo } \\
1 \\
\end{array}$ & 2 & 3 & 4 & 5 & 6 & $\begin{array}{c}\text { Concordo } \\
7 \\
\end{array}$ & Média & Total \\
\hline \multirow{2}{*}{$\begin{array}{l}\text { C9. Minhas aulas são } \\
\text { essencialmente expositivas. }\end{array}$} & $\mathrm{Fi}$ & 17 & 12 & 13 & 28 & 28 & 9 & 6 & 3,8 & 113 \\
\hline & $\%$ & 15 & 11 & 11 & 25 & 25 & 8 & 5 & & 100 \\
\hline \multirow{2}{*}{$\begin{array}{l}\text { C10. Eu utilizo intensamente } \\
\text { seminários com ampla } \\
\text { participação dos alunos em } \\
\text { minhas disciplinas. }\end{array}$} & $\mathrm{Fi}$ & 11 & 7 & 16 & 28 & 24 & 17 & 10 & 4,2 & 113 \\
\hline & $\%$ & 10 & 6 & 14 & 25 & 21 & 15 & 9 & & 100 \\
\hline \multirow{2}{*}{$\begin{array}{l}\text { C11. Eu utilizo de forma intensa } \\
\text { debates com os alunos nas } \\
\text { minhas disciplinas. }\end{array}$} & $\mathrm{Fi}$ & 5 & 2 & 7 & 19 & 21 & 31 & 26 & 5,2 & 111 \\
\hline & $\%$ & 5 & 2 & 6 & 17 & 19 & 28 & 23 & & 100 \\
\hline \multirow{2}{*}{$\begin{array}{l}\text { C12. São realizadas de forma } \\
\text { intensa em minhas disciplinas } \\
\text { discussões de problemas, sendo } \\
\text { que eu e os alunos trabalhamos } \\
\text { juntos na busca de uma solução } \\
\text { para os problemas propostos. }\end{array}$} & $\mathrm{Fi}$ & 2 & 7 & 7 & 18 & 19 & 27 & 32 & 5,3 & 112 \\
\hline & $\%$ & 2 & 6 & 6 & 16 & 17 & 24 & 29 & & 100 \\
\hline \multirow[b]{2}{*}{$\begin{array}{l}\text { C13. Existe um uso intenso de } \\
\text { discussão de casos envolvendo } \\
\text { situações reais do cotidiano } \\
\text { empresarial em minhas } \\
\text { disciplinas, sendo que os alunos } \\
\text { analisam criticamente o assunto } \\
\text { buscando soluções. }\end{array}$} & $\mathrm{Fi}$ & 5 & 4 & 5 & 20 & 14 & 36 & 28 & 5,3 & 112 \\
\hline & $\%$ & 4 & 4 & 4 & 18 & 13 & 32 & 25 & & 100 \\
\hline \multirow{2}{*}{$\begin{array}{l}\text { 14. Existe um uso intenso de } \\
\text { trabalhos em grupo em minhas } \\
\text { disciplinas, sendo que os alunos } \\
\text { interagem com os colegas } \\
\text { para organizar informações e } \\
\text { conhecimentos sobre o conteúdo. }\end{array}$} & $\mathrm{Fi}$ & 3 & 4 & 8 & 20 & 25 & 26 & 26 & 5,2 & 112 \\
\hline & $\%$ & 3 & 4 & 7 & 18 & 22 & 23 & 23 & & 100 \\
\hline \multirow{2}{*}{$\begin{array}{l}\text { C15. Em minhas disciplinas existe } \\
\text { um uso intenso de simulações } \\
\text { (vivências empresariais em } \\
\text { ambientes fictícios com associação } \\
\text { do conhecimento a situações } \\
\text { comuns do ambiente empresarial). }\end{array}$} & $\mathrm{Fi}$ & 4 & 8 & 15 & 21 & 19 & 23 & 22 & 4,8 & 112 \\
\hline & $\%$ & 4 & 7 & 13 & 19 & 17 & 21 & 20 & & 100 \\
\hline
\end{tabular}

Fonte: dados da pesquisa, (2014). 
Observa-se por meio da percepção dos docentes sobre o uso intenso de práticas apresentadas nas afirmações contidas na Tabela 2 que dos 113 respondentes que manifestaram opinião sobre elas, 43 (38\%) manifestaram concordância em utilizar aulas essencialmente expositivas para abordarem o conteúdo em sala (valores assinalados entre 5 e 7 na escala de intensidade); 42 (37\%) não concordam ou concordam parcialmente (valores assinalados entre 1 e 3); e 28 (25\%) mantiveram se neutros (assinalando valor 4). É percebido neste estudo que metodologias como seminários, debates, discussões de problemas, discussão de casos e trabalhos de grupos são mais utilizadas. Conforme dados apresentados na Tabela 2, 51 (45\%); dos 113 respondentes manifestaram positivamente o uso de seminários (concentração de respostas entre 5 e 7); e 28 (25 \%) não se posicionaram nem contra nem a favor (concentração de resposta no nível 4 da escala de concordância). Em seguida debates e Discussão de Casos, com 78 (70\%) dos 112 respondentes concentraram as respostas entre os valores mais altos da escala (assinalaram valores entre 5 e 7 ).

Em linhas gerais, os resultados diferem das ideias de Silva et al. (2013), Pereira, Niyama e Freire (2012), Black (2012), Coetzee e Schmulian (2012), Killian, Huber e Brandon (2012), no que diz respeito à resistência para adotar práticas pedagógicas ativas. Neste estudo, foi encontrado forte utilização de elementos que caracterizam práticas pedagógicas ativas em sala de aula. Contudo, quanto ao planejamento da disciplina, foram encontradas características de um ensino passivo, sendo o professor o apresentador das regras a serem seguidas durante o curso sem a participação dos alunos. Cabe reflexão sobre a maneira como são desenvolvidas as práticas pedagógicas e como os professores utilizam dessas práticas ativas efetivamente em sala de aula, considerando que, na fase inicial de planejamento de tais estratégias, parece não considerar a figura do aluno. É possível que o respondente utilize práticas que deveriam ser ativas, mas com perspectiva passiva; isso quer dizer, que um professor pode adotar, por exemplo, seminários como prática pedagógica para trabalhar em sala e, não, trabalhar de modo a levantar discussões sobre as questões de determinado assunto, apenas transferindo para os alunos a responsabilidade de apresentação de maneira expositiva o conteúdo. Assim tem-se uma prática que deveria ser ativa, sendo utilizada de forma passiva.

Quanto aos recursos utilizados em aulas, foi observado que, em relação ao uso de filmes, 59 (53\%) dos 112 respondentes concentraram as respostas nos valores mais baixos da escala (assinalando valores entre 1 e 3); o mesmo acontece para fotos, gravuras e cartazes, recursos de áudio (músicas, gravações) e utilização de ferramentas digitais de discussão (ferramentas de interação como Moodle, blogs, redes sociais, Skype), sendo que mais de 50\% apontaram discordância no uso intenso destes recursos (assinalando valores entre 1 e 3 na escala de intensidade), conforme apresentado na Tabela 3.

É possível perceber um reduzido uso de filmes, fotos, gravuras e cartazes, recursos de áudio (músicas, gravações) e utilização de ferramentas digitais de discussão (ferramentas de interação como Moodle, blogs, redes sociais, Skype). 
Tabela 3

Recursos utilizados em sala

\begin{tabular}{|c|c|c|c|c|c|c|c|c|c|c|}
\hline & & Discordo 1 & 2 & 3 & 4 & 5 & 6 & Concordo 7 & Média & Total \\
\hline \multirow{2}{*}{$\begin{array}{l}\text { C16. Eu sempre utilizo filmes em } \\
\text { minhas disciplinas. }\end{array}$} & $\mathrm{Fi}$ & 20 & 24 & 15 & 16 & 11 & 12 & 14 & 3,6 & 112 \\
\hline & $\%$ & 18 & 21 & 13 & 14 & 10 & 11 & 13 & & 100 \\
\hline \multirow{2}{*}{$\begin{array}{l}\text { C17. Existe um uso intenso de } \\
\text { fotos, gravuras, cartazes em minhas } \\
\text { disciplinas. }\end{array}$} & $\mathrm{Fi}$ & 22 & 24 & 16 & 22 & 10 & 11 & 7 & 3,3 & 112 \\
\hline & $\%$ & 20 & 21 & 14 & 20 & 9 & 10 & 6 & & 100 \\
\hline \multirow{2}{*}{$\begin{array}{l}\text { C18. Existe um uso intenso de } \\
\text { recursos de áudio (músicas, } \\
\text { gravações) em minhas disciplinas. }\end{array}$} & $\mathrm{Fi}$ & 24 & 26 & 20 & 12 & 13 & 13 & 3 & 3,1 & 111 \\
\hline & $\%$ & 22 & 23 & 18 & 11 & 12 & 12 & 3 & & 100 \\
\hline \multirow{2}{*}{$\begin{array}{l}\text { C19. Existe um uso intenso de } \\
\text { ferramentas digitais de discussão } \\
\text { (ferramentas de interação como } \\
\text { Moodle, blogs, redes sociais, Skype) } \\
\text { em minhas disciplinas. }\end{array}$} & $\mathrm{Fi}$ & 19 & 27 & 19 & 12 & 17 & 11 & 7 & 3,4 & 112 \\
\hline & $\%$ & 17 & 24 & 17 & 11 & 15 & 10 & 6 & & 100 \\
\hline
\end{tabular}

Fonte: dados da pesquisa, (2014)

Retomando a reflexão sobre as práticas pedagógicas ativas sendo usadas em uma perspectiva de ensino passivo, as metodologias apresentadas pelos respondentes como práticas mais adotadas são caracterizadas como metodologias ativas, mas a forma de planejar a disciplina e os recursos utilizados são passivos, o que cabe observar que os respondentes podem adotar práticas ativas e continuarem com a concepção de ensino passivo; ou é possível que a explicação possa ser uma limitação da própria pesquisa em relação ao instrumento e aos respondentes, que pode não querer apresentar as práticas realmente adotadas por eles em sala.

A Tabela 4 apresenta os critérios utilizados para avaliação de desempenho do aluno. Por meio de uma série de afirmações com apresentação de critérios de avaliação de desempenho, sendo apresentada também uma escala de intensidade, com extremos de 1-discordância total e 7-concordância total, para que os respondentes se manifestassem, foi possível observar que os critérios mais utilizados, maior concentração de frequência das respostas entre os valores mais altos da escala (entre 5 e 7) são: Provas Práticas (Simulação Empresarial), com 82 (74\%) dos respondentes; Provas Escritas, com 75 (67\%); Participação dos alunos ao longo das aulas, com 76 (68\%), e Seminários com 61(55\%) dos respondentes. E os critérios menos utilizados são avaliações orais, debates e dinâmicas de grupo com maior concentração de frequência das respostas entre os valores mais baixos da escala (entre 1 e 3 ).

Outra observação: os respondentes utilizam de critérios menos ativos como provas escritas para avaliarem o desempenho do aluno, enquanto critérios ativos como debates, dinâmicas de grupo são pouco utilizados. A explicação para o ensino apresentar características que deveriam ser ativas, mas ao observar a fundo, encontram-se características de um ensino passivo é a possibilidade de o respondente não querer se apresentar como um professor passivo, quando na realidade se atua desta forma. As práticas pedagógicas que caracterizam o modelo tradicional, voltada para o professor e, não, para o aluno e a formação de habilidades reflexivas persistem no ensino superior, conforme Pereira, Niyama e Freire (2012) e Stanley e Marsden (2012). Os resultados apontam características de um ensino passivo, mas com algumas práticas que, se usadas de forma adequada, são de um ensino em uma perspectiva ativa, construtivista. 
Tabela 4

Critérios mais utilizados para avaliação de desempenho dos alunos

\begin{tabular}{|c|c|c|c|c|c|c|c|c|c|c|}
\hline & & Discordo 1 & 2 & 3 & 4 & 5 & 6 & Concordo 7 & Média & Total \\
\hline \multirow{2}{*}{$\begin{array}{l}\text { C20. Eu sempre utilizo provas } \\
\text { escritas como critério de avaliação de } \\
\text { desempenho dos alunos em minhas } \\
\text { disciplinas. }\end{array}$} & $\mathrm{Fi}$ & 6 & 8 & 7 & 15 & 20 & 19 & 36 & 5,1 & 111 \\
\hline & $\%$ & 5 & 7 & 6 & 14 & 18 & 17 & 32 & & 100 \\
\hline \multirow{2}{*}{$\begin{array}{l}\text { C21. Eu utilizo frequentemente } \\
\text { provas práticas ou simulações de } \\
\text { contextos empresariais como critério } \\
\text { de avaliação de desempenho dos } \\
\text { alunos nas minhas disciplinas. }\end{array}$} & $\mathrm{Fi}$ & 5 & 5 & 7 & 12 & 21 & 34 & 27 & 5,2 & 111 \\
\hline & $\%$ & 5 & 5 & 6 & 11 & 19 & 31 & 24 & & 100 \\
\hline \multirow{2}{*}{$\begin{array}{l}\text { C22. Eu utilizo frequentemente } \\
\text { seminários para avaliar o } \\
\text { desempenho dos alunos nas minhas } \\
\text { disciplinas. }\end{array}$} & $\mathrm{Fi}$ & 10 & 15 & 9 & 15 & 20 & 21 & 20 & 4,5 & 110 \\
\hline & $\%$ & 9 & 14 & 8 & 14 & 18 & 19 & 18 & & 100 \\
\hline \multirow{2}{*}{$\begin{array}{l}\text { C23. Eu utilizo avaliações orais como } \\
\text { critério de avaliação de desempenho } \\
\text { dos alunos nas minhas disciplinas. }\end{array}$} & $\mathrm{Fi}$ & 34 & 24 & 6 & 13 & 13 & 9 & 10 & 3,1 & 109 \\
\hline & $\%$ & 31 & 22 & 6 & 12 & 12 & 8 & 9 & & 100 \\
\hline \multirow{2}{*}{$\begin{array}{l}\text { C24. Existe um uso muito frequente } \\
\text { de debates como critério de avaliação } \\
\text { de desempenho dos alunos nas } \\
\text { minhas disciplinas. }\end{array}$} & $\mathrm{Fi}$ & 17 & 11 & 16 & 20 & 25 & 8 & 13 & 3,9 & 110 \\
\hline & $\%$ & 15 & 10 & 15 & 18 & 23 & 7 & 12 & & 100 \\
\hline \multirow{2}{*}{$\begin{array}{l}\text { C25. Existe um uso muito frequente } \\
\text { de dinâmicas de grupo como critério } \\
\text { de avaliação de desempenho dos } \\
\text { alunos nas minhas disciplinas. }\end{array}$} & $\mathrm{Fi}$ & 16 & 16 & 15 & 16 & 21 & 14 & 13 & 3,9 & 111 \\
\hline & $\%$ & 14 & 14 & 14 & 14 & 19 & 13 & 12 & & 100 \\
\hline \multirow{2}{*}{$\begin{array}{l}\text { C26. Eu sempre utilizo a participação } \\
\text { dos alunos ao longo das aulas como } \\
\text { critério de avaliação de desempenho } \\
\text { dos alunos nas minhas disciplinas. }\end{array}$} & $\mathrm{Fi}$ & 9 & 7 & 8 & 11 & 20 & 20 & 36 & 5,1 & 111 \\
\hline & $\%$ & 8 & 6 & 7 & 10 & 18 & 18 & 32 & & 100 \\
\hline
\end{tabular}

Fonte: dados da pesquisa, 2014

Não foi possível caracterizar o modelo de ensino nas instituições de Ensino da Bahia como ensino baseado somente na perspectiva tradicional, passiva ou caracterizado como modelo ativo de ensino, práticas ativas apenas. Há uma utilização de práticas passivas e ativa, quando se trata de planejamento das disciplinas com características de ensino passivo. Já no que se refere à forma de ministrar as aulas, os resultados apontam forte utilização de práticas ativas. Cabe reflexão sobre a maneira como são desenvolvidas as práticas pedagógicas e como os professores utilizam essas práticas ativas efetivamente em sala de aula, considerando que na fase inicial de planejamento de tais estratégias, parecem não considerar a figura do aluno. É possível que o respondente utilize de práticas que deveriam ser ativas, mas com perspectivas passivas, isso quer dizer, que um professor pode adotar, por exemplo, seminários como prática pedagógica para trabalhar em sala, mas não trabalha de forma a levantar discussões sobre as questões de determinado assunto, apenas transferem para os alunos a responsabilidade de apresentação de forma expositiva o conteúdo. Assim tem-se uma prática que deveria ser ativa, sendo utilizada de forma passiva. 
É importante pensar se a aplicação das práticas pedagógicas ativas acontece efetivamente na realidade em sala de aula com o propósito de promover maior interação entre professor e aluno. Existe a possibilidade de um docente adotar práticas que são características de um ensino ativo, entretanto no momento de desenvolvê-la em sala de aula pode ser conduzida de forma passiva. Para Marion, Garcia e Cordeiro (1999), quando se referem a práticas pedagógicas no ensino de Contabilidade, a utilização de seminários não é simplesmente a apresentação de determinado tema e, sim, as indagações surgidas, quando devem ser criadas condições para discussões e conduzir os alunos ao debate. Outra observação é quanto à utilização de estudo de casos como práticas pedagógicas. Para esses autores, os casos deveriam ser reais para promover um contato com o dia a dia no ambiente de negócios e que "nem sempre os casos tirados de livros e principalmente da literatura estrangeira atendem às necessidades regionais e culturais dos estudantes" (Marion, Garcia \& Cordeiro, 1999, p.31).

No que tange aos recursos utilizados, pouca utilização de recursos que promovem maior interação, como filmes, fotos, gravuras e cartazes, recursos de áudio (músicas, gravações) e ferramentas digitais de discussão (ferramentas de interação como Moodle, blogs, redes sociais, Skype). Quanto aos critérios de avaliação de desempenho dos alunos, foram observados critérios passivos e ativos utilizados de forma intensa como Provas Práticas (Simulação Empresarial), Provas Escritas e Seminários com média.

Posteriormente, as repostas do Bloco C permitiram segregar os respondentes em dois grupos, a partir das concepções pedagógicas empregadas. As afirmações do bloco $\mathrm{C}$ faziam sempre referência ao ensino ativo, com exceção das afirmações C9 ("Minhas aulas são essencialmente expositivas") e C20 ("Eu sempre utilizo provas escritas como critério de avaliação de desempenho dos alunos em minhas disciplinas"). Nestes dois casos, foram calculadas duas novas variáveis denominadas C9Invertida e C20Invertida. Cada uma das variáveis invertidas foi calculada mediante a subtração da variável original de 8 (C9Inverti$\mathrm{da}=8-\mathrm{C} 9$ e C20Invertida $=8-\mathrm{C} 20$ ). Posteriormente, calculou-se a média formada pelas duas variáveis invertidas e pelas outras 24 variáveis originais. A mediana das médias das questões do bloco $\mathrm{C}$ foi igual a 4,775 , permitindo segregar os respondentes em dois grupos, aqui apresentados como possuidores de concepções mais passivas ou mais ativas. Os postos médios das variáveis independentes foram comparados com uso do teste não paramétricos de Mann Whitney, conforme apresenta a Tabela 5. 
Tabela 5

Testes de Mann-Whitney

\begin{tabular}{|c|c|c|c|c|c|}
\hline \multicolumn{2}{|c|}{ Concepções usadas } & \multirow{2}{*}{$\begin{array}{l}\mathbf{N} \\
54\end{array}$} & \multirow{2}{*}{$\begin{array}{c}\text { Posto médio } \\
55,20 \\
\end{array}$} & \multirow{2}{*}{$\begin{array}{c}\text { Soma dos Postos } \\
2981,00 \\
\end{array}$} & \multirow{2}{*}{$\begin{array}{c}\begin{array}{c}\text { Mann-Whitney U, Z } \\
\text { e Sig }\end{array} \\
1420 \\
\end{array}$} \\
\hline \multirow{3}{*}{ Tipo de IES (públicas, privadas). } & Mais passivas & & & & \\
\hline & Mais ativas & 54 & 53,80 & 2905,00 & $-0,272$ \\
\hline & Total & 108 & & & 0,785 \\
\hline \multirow{3}{*}{$\begin{array}{l}\text { Modalidade (distância, } \\
\text { presencial) }\end{array}$} & Mais passivas & 55 & 58,68 & 3227,50 & 1282,5 \\
\hline & Mais ativas & 54 & 51,25 & 2767,50 & $-1,945$ \\
\hline & Total & 109 & & & 0,052 \\
\hline \multirow{3}{*}{ Atividades profissionais (anos) } & Mais passivas & 55 & 58,95 & 3242,00 & 1268 \\
\hline & Mais ativas & 54 & 50,98 & 2753,00 & $-1,317$ \\
\hline & Total & 109 & & & 0,188 \\
\hline \multirow{3}{*}{$\begin{array}{l}\text { Atividades profissionais em } \\
\text { Contabilidade (anos) }\end{array}$} & Mais passivas & 53 & 55,88 & 2961,50 & 1119,5 \\
\hline & Mais ativas & 50 & 47,89 & 2394,50 & $-1,359$ \\
\hline & Total & 103 & & & 0,174 \\
\hline \multirow{3}{*}{$\begin{array}{l}\text { Conteúdo } \\
\text { (teórica, prática) }\end{array}$} & Mais passivas & 55 & 53,36 & 2935,00 & 1395 \\
\hline & Mais ativas & 54 & 56,67 & 3060,00 & $-0,556$ \\
\hline & Total & 109 & & & 0,578 \\
\hline \multirow{3}{*}{ Quantidade de alunos } & Mais passivas & 49 & 51,27 & 2512,00 & 1114 \\
\hline & Mais ativas & 49 & 47,73 & 2339,00 & $-0,622$ \\
\hline & Total & 98 & & & 0,534 \\
\hline \multirow{3}{*}{$\begin{array}{l}\text { Grau de avanço no curso (início, } \\
\text { final) }\end{array}$} & Mais passivas & 55 & 51,39 & 2826,50 & 1286,5 \\
\hline & Mais ativas & 55 & 59,61 & 3278,50 & $-1,374$ \\
\hline & Total & 110 & & & 0,169 \\
\hline \multirow{3}{*}{$\begin{array}{l}\text { Disciplinas pedagógicas na } \\
\text { graduação }(\mathrm{h})\end{array}$} & Mais passivas & 25 & 27,02 & 675,50 & 299,5 \\
\hline & Mais ativas & 26 & 25,02 & 650,50 & $-0,491$ \\
\hline & Total & 51 & & & 0,624 \\
\hline \multirow{3}{*}{$\begin{array}{l}\text { Disciplinas pedagógicas na } \\
\text { especialização (h) }\end{array}$} & Mais passivas & 37 & 34,62 & 1281,00 & 578 \\
\hline & Mais ativas & 36 & 39,44 & 1420,00 & $-0,979$ \\
\hline & Total & 73 & & & 0,328 \\
\hline \multirow{3}{*}{$\begin{array}{l}\text { Disciplinas pedagógicas no } \\
\text { mestrado }(\mathrm{h})\end{array}$} & Mais passivas & 26 & 24,96 & 649,00 & 298 \\
\hline & Mais ativas & 25 & 27,08 & 677,00 & $-0,512$ \\
\hline & Total & 51 & & & 0,609 \\
\hline
\end{tabular}

Fonte: dados da pesquisa (2014).

Em linhas gerais, todas as diferenças de postos médios apresentadas na Tabela 5 foram não significativas, indicando que as variáveis independentes (capacitação e experiência pedagógica do docente, tipo de IES, modalidade de ensino, conteúdo, quantidade de alunos na turma e grau de avanço no curso) seriam incapazes de explicar ou predizer uma prática pedagógica mais ativa ou passiva. 


\section{Considerações Finais}

Este trabalho identificou as práticas pedagógicas utilizadas no cotidiano de 164 professores do curso de Ciências Contábeis do Estado da Bahia e sua eventual associação com as variáveis: capacitação pedagógica; tipo de instituição de ensino; modalidade de ensino; experiência docente; conteúdo programático; quantidade de alunos e grau de avanço no curso. Por meio do teste de Mann-Whitney e análise de frequência como procedimentos para análise dos resultados encontrados foram testadas as sete hipóteses apresentadas para este estudo. De modo geral, não foi possível constatar a associação das variáveis estabelecidas e as práticas pedagógicas de docentes classificados como possuidores de práticas mais passivas ou mais ativas.

E o que é "que me ensina a ensinar", conforme o título proposto para o presente trabalho? Originalmente, a pretensão seria a de apresentar uma resposta a partir de variáveis associadas ao meio (tipo de IES, modalidade de ensino, conteúdo, quantidade de alunos na turma e grau de avanço no curso) ou ao docente (capacitação e experiência pedagógica). Os procedimentos e testes estatísticos feitos foram incapazes de fornecer respostas claras em relação às variáveis propostas. Conforme a proposta original da pesquisa, não seria possível precisar sobre o "que me ensina a ensinar".

Contudo, ao observar a caracterização das práticas pedagógicas, resultados controversos são exibidos. A caracterização do planejamento das disciplinas, da maneira como são conduzidas as aulas, dos recursos utilizados e dos critérios adotados para avaliação de desempenho dos alunos indicou a existência de práticas pedagógicas ativas. No entanto, em relação ao planejamento da disciplina, foram encontradas características de um ensino passivo, com o professor apresentando as regras a serem seguidas durante o curso sem a participação dos alunos. Os respondentes assumem adotar práticas pedagógicas ativas.

Contudo, em sua fase inicial de planejamento pedagógico atuam de forma passiva. Os recursos utilizados pelos respondentes possuem características de ensino passivo. Existe a possibilidade de que os respondentes possam adotar práticas (como uso de filmes ou seminários) que deveriam estar encaixadas em um contexto ativo, com forte envolvimento discente, contudo o uso pode estar ocorrendo em uma perspectiva passiva (preenchendo horas "ociosas" ou sem o devido envolvimento do docente e dos discentes). Nestas situações, a efetividade do processo de ensino poderia estar comprometida. Ilustrando, quando os seminários não são utilizados de forma bem encaixada e planejada no contexto da disciplina, deixam de ser um espaço para reflexão e passam a ser apenas uma transferência de responsabilidade para o aluno apresentar o conteúdo para os demais integrantes da turma, conforme critérios estabelecidos pelo professor. Logo, práticas pedagógicas que deveriam caracterizar o ensino como ativo podem estar sendo utilizadas como forma passiva de ensinar.

Neste contexto, seria possível supor que hiatos de formação pedagógica (desconhecimento sobre como práticas ativas deveriam estar inseridas no processo de ensino) ou de comprometimento do docente com o processo educacional (ocupando o tempo das aulas sem uma preocupação efetiva com as práticas adotadas) poderiam estar "ensinando a ensinar". Estas inquietações podem direcionar futuras pesquisas. Novas abordagens podem ser feitas, incluindo outras variáveis que possam explicar a adoção de práticas pedagógicas como os modelos pedagógicos vivenciados pelos docentes durante sua trajetória formativa.

Faz-se necessário refletir sobre as práticas pedagógicas e os resultados da atuação docente em sintonia com as exigências do mercado, considerando as competências e habilidades requeridas para a atuação profissional. O contador é mais do que um profissional com uma bagagem de conteúdos; precisa saber como aplicá-lo da melhor forma considerando as contingências do ambiente em que está inserido. Na realidade prática, o contador lida tecnologias de informação e comunicação que exige atitudes que envolvam habilidades de persuasão raciocínio lógico. $\mathrm{O}$ ambiente econômico e social também influencia a atuação profissional, visto que as empresas estão inseridas em um contexto social. 


\section{Referências}

Black, W. H. (2012). The Activities of the Pathways Commission and the Historical Context for Changes in Accounting Education. Issues in Accounting Education, 27(3), pp. 601-625. doi: 10.2308/iace-50091.

Coetzee, S. A. \& Schmulian, A. (2012). A Critical Analysis of the Pedagogical Approach Employed in an Introductory Course to IFRS. Issues in Accounting Education, 27(1), pp. 83-100. doi: 10.2308/iace10220.

Cunningham, Billie M. (2011). Introductory Accounting as Theater: A Look Behind the Scenes of Large-Lecture Production. Issues in Accounting Education, 26(4), pp. 815-833. doi: http://dx.doi. org/10.2308/iace-50069

Dellaportas, S. \& Hassall, T. (2013). Experiential learning in accounting education: A prison visit. The British Accounting Review, 45(1), pp. 24-36. doi: 10.1016/j.bar.2012.12.005.

Freire, P. (1987). Pedagogia do oprimido (17 a ed). Rio de Janeiro: Paz e Terra.

Killian, L. J.; Huber, M. M \& Brandon, C. D. (2012). The Financial Statement Interview: Intentional Learning in the First Accounting Course. Issues in Accounting Education, 27 (1), pp. 337-360. doi: $10.2308 /$ iace- 10220 .

Kosová, B. (2014). Contemporary dilemmas in university and academic education: a central european perspective. Human Affairs, 24, pp. 68-77. doi: http://dx.doi.org/10.2478/s13374-014-0206-0

Magalhães, F. A. S; Santos, R. C. \& Costa, F. M. (2010). IAS 36 - Redução ao valor recuperável de ativos. Ernst\& Young. Fipecafi. Manual de normas internacionais de Contabilidade ( $2^{\mathrm{a}}$ ed.). São Paulo: Atlas.

Maringe, F. \& Sing, N. (2014). Teaching large classes in an increasingly internationalising higher education environment: pedagogical, quality and equity issues. Higher Education, 67(6), pp. 761-782. doi: http://dx.doi.org/10.1007/s10734-013-9710-0

Marion, J. C.; Garcia, E. \& Cordeiro, M. (1999). Discussão sobre metodologias de ensino aplicáveis à contabilidade. Contabilidade Vista e Revista, 10 (1), pp. 28-33.

Martins, O. S.; Vasconcelos, A. F.\& Monte, P. A. (2009). IES Pública X IES Privada: Uma Investigação Sobre o Mito da Influência do Tipo de IES na Atuação Profissional do Contador. Contabilidade Vista \& Revista, 20 (2), 39-64.

Masetto, M. T. (2009). Formação Pedagógica dos Docentes do Ensino Superior. Revista Brasileira de Docência, Ensino e Pesquisa em Administração, 1(2), pp. 04-25.

Miranda, G. J.; Casa Nova, S. P. C. \& Cornacchione Junior, E. B. (2012). Os saberes dos professores-referência no ensino de Contabilidade. Revista de Contabilidade e Finanças, 23(59), pp. 142-153. doi: http://dx.doi.org/10.1590/S1519-70772012000200006

Nóvoa, A. (2009) Para uma formação de professores construída dentro da profissão. Educación. 350, pp. 203-18.

Oliveira, C. B. (2009). Uma análise das evidências da aplicação do proceder sóciointeracionista de Vygotsky nos cursos de graduação de Ciências Contábeis, nos Estados da Paraíba e Pernambuco. Dissertação de mestrado, Universidade Federal de Pernambuco, Recife, PE, Brasil.

Peléias, I. R.; Petrucci, V.B.C.; Garcia, M.N. \& Silva, Dirceu. (2008). Pesquisa sobre a percepção dos alunos do $1^{\circ}$ ano de Ciências Contábeis na cidade de São Paulo em relação às dificuldades por eles percebidas no período noturno. Revista Universo Contábil, 4(1), pp. 81-94.

Pereira, E. M.; Niyama, J. K. \& Freire, F. S. (2012). Uma análise a luz das teorias da educação de Paulo Freire e Libaneo nas Instituições de Ensino do Distrito Federal. Anais do Congresso USP de Controladoria e Contabilidade. São Paulo, SP, Brasil, 12. 
Petrucci, V. B. C.I \& Batiston, R. R. (2006). Estratégias de ensino e avaliação de aprendizagem em Contabilidade. Peléias, Ivan Ricardo (Org.). Didática do ensino da Contabilidade. São Paulo: Saraiva.

Premuroso, R. F.; Tong, L. \& Beed, T. K. (2011). Does Using Clickers in the Classroom Matterto Student Performance and Satisfaction When Taking the Introductory FinancialAccounting Course? Issues in Accounting Education, 26(4), pp. 701-723, doi: http://dx.doi.org/10.2308/iace-50069

Silva, F. L. (2001). Reflexões sobre o conceito e a função da universidade pública. Estudos avançados, 15(42), pp. 295-304. doi: 10.1590/S0103-40142001000200015.

Silva, U. B.; Bruni, A.L. \& Baqueiro, A.G.M. (2013) Concepções Pedagógicas e mudanças nas Práticas Contábeis: um estudo sobre o Modelo Educacional adotado em uma universidade pública e a formação crítico-reflexiva do Contador. Anais do Congresso Anpcont, Fortaleza, CE, Brasil, 7.

Silva, U. B. (2014). Aprenda o que eu ensino, mas não ensine o que eu aprendo: percepções e constatações no ensino de contabilidade da Bahia. Dissertação de mestrado, Universidade Federal da Bahia, Salvador, BA, Brasil.

Slomski, V. G. (2007). Saberes e competências do professor universitário: contribuições para o estudo da prática pedagógica do professor de Ciências Contábeis do Brasil. Revista de Contabilidade e Organizações, 1(1), p. 89.

Slomski, V. G. \& Martins, G. A. (2008). O conceito de professor investigador: os saberes e as competências necessárias à docência reflexiva na área contábil. Revista Universo Contábil, 4(4), pp. 06-21.

Stanley, T. \& Marsden, S. (2012). Problem-based learning: Does accounting education need it?. Journal of Accounting. Education, 30(2), pp. 267-289. doi: http://dx.doi.org/10.1016/j.jaccedu.2012.08.010

Tozetto, S. S.\& Gomes, T.S. (2009). A prática pedagógica na formação docente. Revista Reflexão e Ação. $17(2)$.

Veiga, I. P.A. (2008) A prática pedagógica do professor de didática (11ª ed.). Campinas: Papirus.

Zanon, D. P. \& Althaus, M. T. M. (2010). Possibilidades didáticas do trabalho com o seminário na aula universitária. Anais do Encontro de Pesquisa em Educação da Região Sul - Anpedsul. Londrina, PR, Brasil, 8. 